\title{
Comparison of two measurement methods for the determination of extended turbine maps at the eATL test bench of the Ostfalia UAS
}

This document compares two measurement methods for the determination of extended turbine maps. One method is to minimize heat flows and thus to maintain the assumption of adiabatic processes even in low speed ranges of turbines. The results obtained were compared with those of the Ostfalia eATL method. Here, is slowed down electrically by an electric motor. The direct comparison of the measurement results shows considerable differences in the turbine efficiency. Furthermore, the graphical comparison illustrates clear advantages of the eATL concept for the evaluation, which result from the width and the position of the generated measurement points.

Key words: turbocharger, hot gas test bench, heat flows, extended turbine maps

\section{Introduction and motivation}

Because of exhaust emission laws, which become more and more strictly, it is necessary to optimize the current engines until alternate engine concepts are competitive. In recent years downsizing of combustion engines become established. Turbochargers are mainly used to compensate the horsepower losses resulting from the reduced engine sizes.

Turbine maps and compressor maps are required for choosing a turbocharger well-matched to the selected engine. These maps commonly were generated on hot gas test benches. In praxis it's proposed to approximate engine requirements for measuring. But there are no standardized norms for generating turbine and compressor maps. In many cases the measurements are performed as descripted in guidelines such as SAE J922 [7] or SAE J1826 [8]. But in both guidelines are missing detailed descriptions about the setup of the section of measurements and measuring point assembly. They equally leave recommendation on minimizing heat flows of turbochargers out of consideration [5].

Various influences have an impact on turbocharger parameters during generating the maps. However these parameters cannot determine straightaway. They have to calculate from the steady conditions pressure, temperature, mass flow and air humidity. Ideally the parameters can describe the thermo- and aerodynamic performance of the turbocharger. Likewise the reproducibility and comparability have to be exactly. But in practice this could be a conflict of goals, because of the differences of each turbocharger and the associated differences in measuring tubes, metrology and system boundaries (Fig. 1) [9].

Heat flows within the turbocharger have a wide influence on the level of efficiency of compressor and turbine. For generating the turbine and compressor maps it is generally adopted, that turbine and compressor are adiabatic units. This method achieves reliable results at high speeds. If the rotational speed decelerates (less than $30 \%$ of maximum rotational speed) the turbine efficiency will falsify the results because of heat flows. Similarly the adiabatic adoption for turbine and compressor declines. Therefore special measuring methods are required in low speed ranges. [1] The maps with low speed ranges are so-called extended turbine maps. The additional data points of the diagrams enable detailed und quite extrapolations of the turbine efficiency. Furthermore, the information is needed to characterize the behaviour of the turbine within its entire speed range. So it's possible to optimize the engine process simulation.

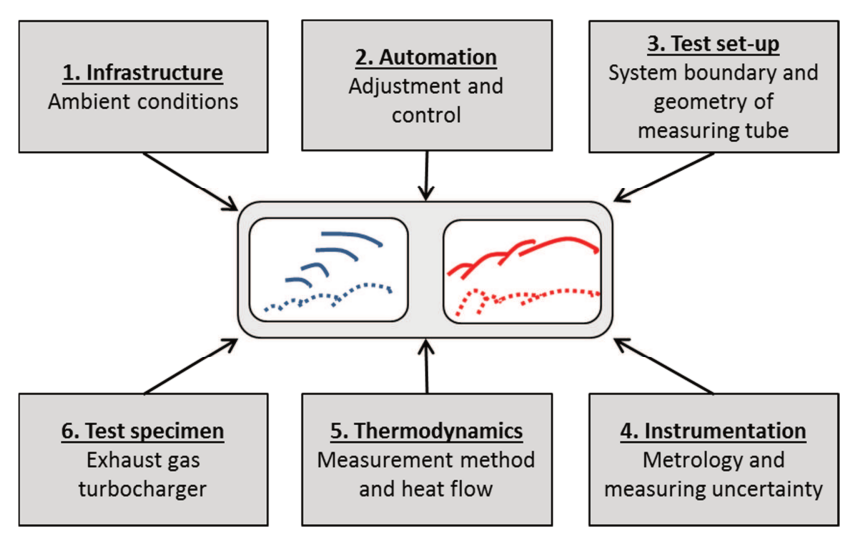

Fig. 1. Ranking of the influencing factors of parameters of a turbocharger on a hot gas test bench by generating characteristing maps, based on [5]

This document compares two measurement methods directly and indicates the obtained results. Both methods intend to reduce the effects of heat transfer on turbine efficiency at low speed ranges. The first approach used for the comparison is based on conventional procedures on hot gas test benches. As on common configurations the turbine is braked down by the compressor. As opposed to common measurements, adiabatic conditions are aspired to reduce heat flows within the turbocharger. On the second procedure the compressor is replaced by an electric motor, so the influences of heat flows on the compressor side are completely eliminated.

\section{Mathematical method}

According to custom on common test benches, both experiments were run under steady-state conditions. [3] The pictured turbine maps are based on calculated turbine efficiencies. The specific ways the turbine efficiencies are determined are explained below. 
Adiabatic: The turbine efficiency of turbochargers commonly is defined by the ratio of outputs of turbine and compressor on standard test benches [2]. For the adiabatic criterion the isentropic turbine efficiency $\eta_{\mathrm{ts}, \mathrm{T}, \mathrm{is}}$ is defined as the dividend of measured compressor output $\mathrm{P}_{\mathrm{C}}$ and the calculated isentropic turbine output $\mathrm{P}_{\mathrm{ts}, \mathrm{T}, \mathrm{is}} \mathrm{s}$ :

$$
\eta_{\mathrm{ts}, \mathrm{T}, \text { is }}=\frac{\mathrm{P}_{\mathrm{C}}}{\mathrm{P}_{\mathrm{ts}, \mathrm{T}, \mathrm{is}}}
$$

The compressor output computates from the specific heat capacity $\mathrm{c}_{\mathrm{p}, \mathrm{C}}$ and the air mass flow $\dot{\mathrm{m}}_{\mathrm{C}}$ multiplied with the difference of the measured temperatures $T_{t, 2}$ and $T_{t, 1}$ :

$$
\mathrm{P}_{\mathrm{C}}=\dot{\mathrm{m}}_{\mathrm{C}} \cdot \mathrm{c}_{\mathrm{p}, \mathrm{C}} \cdot\left(\mathrm{T}_{\mathrm{t}, 2}-\mathrm{T}_{\mathrm{t}, 1}\right)
$$

The isentropic turbine output $\mathrm{P}_{\mathrm{ts}, \mathrm{T}, \text { is }}$ computates from the specific heat capacity $\mathrm{c}_{\mathrm{p}, 3}$, the measured temperature $T_{t, 3}$ and the inverted turbine pressure ratio $\Pi_{t s, T}$, which substitutes the isentropic turbine temperature:

$$
\mathrm{P}_{\mathrm{ts}, \mathrm{T}, \mathrm{is}}=\dot{\mathrm{m}}_{\mathrm{T}} \cdot \mathrm{c}_{\mathrm{p}, 3} \cdot \mathrm{T}_{\mathrm{t}, 3} \cdot\left(1-\left(\frac{1}{\Pi_{\mathrm{ts}, \mathrm{T}}}\right)^{\frac{\kappa-1}{\kappa}}\right)
$$

Equation (2.2) combined with equation (2.3) results in the turbine efficiency $\eta_{\mathrm{ts}, \mathrm{T}, \mathrm{is}}$ :

$$
\eta_{\mathrm{ts}, \mathrm{T}, \mathrm{is}}=\frac{\dot{\mathrm{m}}_{\mathrm{C}} \cdot \mathrm{c}_{\mathrm{p}, \mathrm{C}} \cdot\left(\mathrm{T}_{\mathrm{t}, 2}-\mathrm{T}_{\mathrm{t}, 1}\right)}{\dot{\mathrm{m}}_{\mathrm{T}} \cdot \mathrm{c}_{\mathrm{p}, 3} \cdot \mathrm{T}_{\mathrm{t}, 3} \cdot\left(1-\left(\frac{1}{\Pi_{\mathrm{ts}, \mathrm{T}}}\right)^{\frac{\kappa-1}{\kappa}}\right)}
$$

The measured values used for calculating the isentropic turbine output yield solid results. But the compressor power can be manipulate the measured data because of heat flows. Especially in test bench operation with hot gas at low rotational speeds, the measured compressor output is incorrect for the reason that there are heat flows by the warmer turbine side. As a result the turbine efficiency is also distorted. Because of the heat input the adiabatic method operates with fluids approximated to ambient temperature. So it's possible to reduce the error risk.

Ostfalia eATL: In this setup an electric motor displaces the compressor housing and rotor. So it's possible to get the isentropic turbine efficiency directly from the electrical power $\mathrm{P}_{\mathrm{T}, \mathrm{eATL}}$ divided by the isentropic turbine output:

$$
\eta_{\mathrm{T}, \mathrm{eATL}}=\frac{\mathrm{P}_{\mathrm{T}, \mathrm{eATL}}}{\mathrm{P}_{\mathrm{ts}, \mathrm{T}, \mathrm{is}}}
$$

To calculate the electrical power it is simply necessary to measure the torque $\mathrm{M}_{\mathrm{ATL}}$ und rotational speed $\mathrm{n}_{\mathrm{ATL}}$ of the turbocharger shaft:

$$
\mathrm{P}_{\mathrm{T}, \mathrm{eATL}}=2 \cdot \pi \cdot \mathrm{M}_{\mathrm{ATL}} \cdot \mathrm{n}_{\mathrm{ATL}}
$$

Equation (2.6) combined with equation (2.3) results in the turbine efficiency:

$$
\eta_{\mathrm{T}, \mathrm{eATL}}=\frac{2 \cdot \pi \cdot \mathrm{M}_{\mathrm{ATL}} \cdot \mathrm{n}_{\mathrm{ATL}}}{\dot{\mathrm{m}}_{\mathrm{T}} \cdot \mathrm{c}_{\mathrm{p}, 3} \cdot \mathrm{T}_{\mathrm{t}, 3} \cdot\left(1-\left(\frac{1}{\Pi_{\mathrm{ts}, \mathrm{T}}}\right)^{\frac{\kappa-1}{\kappa}}\right)}
$$

\section{Creation of turbine maps}

There is a certain range to create turbine maps. An established method is to plot the turbine efficiency as a function of velocity ratio $\varphi_{\mathrm{T}}$. The velocity ratio can be calculated as a quotient of peripheral speed of turbine wheel $u_{T}$ and flow velocity $\mathrm{c}_{0} \cdot[2]$

$$
\varphi_{\mathrm{T}}=\frac{\mathrm{u}_{\mathrm{T}}}{\mathrm{c}_{0}}
$$

The peripheral speed of the turbine wheel is the product of turbine wheel diameter $\mathrm{d}_{\mathrm{T}}$ and rotational speed of turbocharger $\mathrm{n}_{\mathrm{ATL}}$.

$$
\mathrm{u}_{\mathrm{T}}=\pi \cdot \mathrm{d}_{\mathrm{T}} \cdot \mathrm{n}_{\mathrm{ATL}}
$$

With the isentropic turbine output $\mathrm{P}_{\mathrm{T}, \text { is }}$ and the air mass flow of turbine $\dot{\mathrm{m}}_{\mathrm{T}}$ the flow velocity can be compute.

$$
\mathrm{c}_{0}=\sqrt{\frac{2 \cdot \mathrm{P}_{\mathrm{T}, \mathrm{is}}}{\dot{\mathrm{m}}_{\mathrm{T}}}}
$$

Two more points are needed for generating the characteristic curve for the turbine efficiency. These two points stand for a turbine efficiency level of $0 \%$.

\section{Test bench setup}

For the comparison of both methods the setups were operated with the same turbocharger on the Ostfalia University of Applied Sciences (Ostfalia UAS). The general structure of the test bench corresponds largely to conventional hot gas test benches. To supply the turbocharger turbine with air a Root's compressor compresses ambient air. Optional it is possible to heat the air in a heating chamber which is operated by electricity. All required parameters for the calculation were measured accurately. A high-precision measuring device records ambient pressure $\mathrm{p}_{0}$, ambeint temperature $\mathrm{T}_{0}$, humidity $\varphi_{0}$ and the mass flow $\dot{\mathrm{m}}_{\mathrm{T}}$. These paremeters are the basis for setting the desired measuring point. It is also possible to modify pressure and temperature of the oil for the turbocharger bearing by using an oil conditioner. The specific test setup for each method is explained below.

Adiabatic: The setup for the adiabatic measurement of the Ostfalia UAS test bench is shown in Fig. 2.

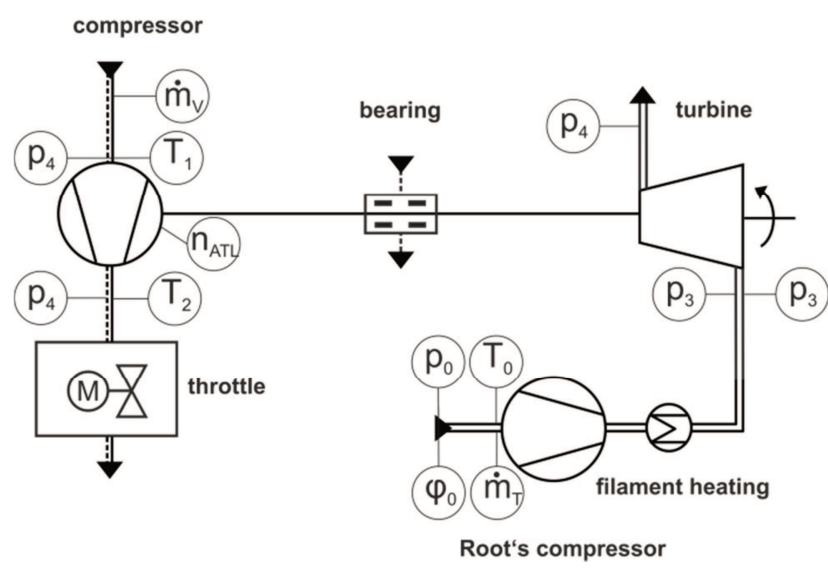

Fig. 2. Test bench setup "adiabatic" 
The entire turbocharger is built in the test bench. So the compressor breaks down the turbine. The compressor output is adjusted by a throttle which is arranged behind. So it's possible to modify the compressor mass flow for adjusting the compressor output. Because of the adiabatic criterion, the heating chamber is not in use. But because of the compression of the gas a heat build-up is resulting. In this setup of the test bench it is not possible to act contrary to the heating of the air. But there were the possibility for using the inertness of the heating chamber. The tube following this chamber includes the measuring points for pressure and temperature in front of the turbine. The turbine exhaust contains a temperature measuring point, too. On the compressor side are measuring points for temperature and pressure behind and in front of the compressor wheel. In front of the compressor is a longer tube to succeed a steady flow. So the precision of measurements of airflow increases. An airflow sensor is determined in front of the compressor. The compressor housing features a sensor, which detects the rotational frequency of the compressor wheel.

eATL: The setup for the eATL measurement of the Ostfalia UAS test bench is shown in Fig. 3. Instead of the compressor wheel and the compressor housing an electric motor is installed. For this configuration the compressor housing is dismantled and the compressor wheel is eroded. A coupling combines the shafts of the turbocharger and the electric motor. In combination with an electric load the emotor can be switched to a generator. So it's possible to break down the turbine. The torque generated by breaking down the turbine is measured with a torque sensor. The shaft torque is measured by the reaction force of the emotor. Sensor and e-motor are fixed permanently, so the reaction force is measured with a Wheatstone bridge with resistive wire strain. The shaft frequency is measured with an inductive speed sensor. The e-motor features a watercooled cladding, which protects it from overheating because of much power ratings resulting from high rotational speeds or high electrical loads. To compensate axial and radial offsets of both shafts (e-motor and turbocharger shafts) a special socket is appointed. On this socket e-motor and torque sensor are applied. The seating consists of three linear units, which enable axial alignment on $\mathrm{x}-$, $\mathrm{y}-$ and $\mathrm{z}-$ axis. The measuring points behind and in front of the turbine are identically equal to the adiabatic test bench setup. But the measuring points around the compressor are omitted.

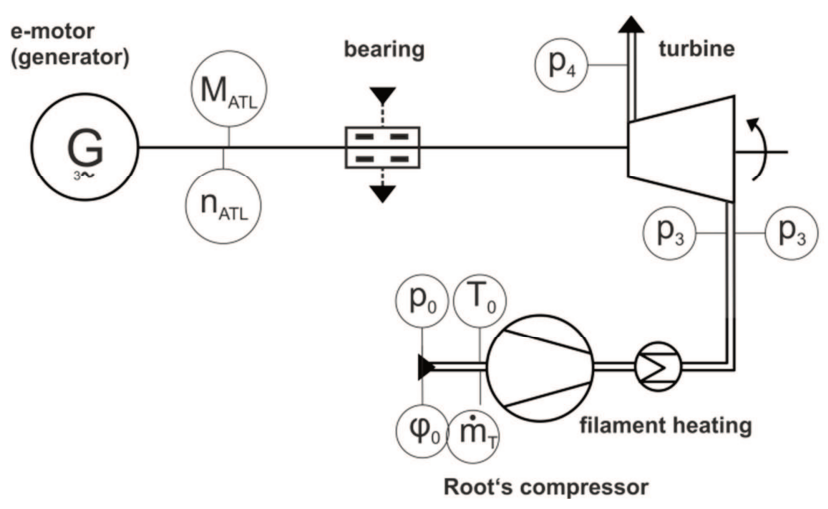

Fig. 3. Test bench setup "eATL"
Measurement conditions: The tested turbocharger is one with wastegate adjustment. Because of the comparability of both measurement methods, the terms and conditions of the eATL were transferred to the adiabatic setup. So all fluids were unheated and round about ambient conditions (approximately $20^{\circ} \mathrm{C}$ ). Sole exception is the compacted air for the turbine. It increased because of the pressure rise resulting from the Root's compressor. But the temperature was not higher than $32^{\circ} \mathrm{C}$.

For generating extended turbine maps in low speed levels the rotational speeds 20000; 40000; 60000 and 80000 rpm were investigated.

\section{Measurement results}

The test readings are shown in diagrams with velocity ratio on $\mathrm{x}$-coordinate and isentropic turbine efficiency on $\mathrm{y}$ axis. Because of increasing the brakeload of each series of measurement, the maps and graphs have to be read from right side to left side. For the beginning the results of both measurement methods are shown separately.

Adiabatic: The generated meter points are shown in Fig. 4. The increase in the efficiency with the increase of the rotational speed seems to be plausible and corresponds to the expectation. The maximum efficiency is around $48 \%$ and is reached with $80000 \mathrm{rpm}$ as expected at the highest speed. You can see that the measured points of all series are located in a narrow margin. This results from the low braking power which the compressor is able to provide. For illustrating the compressor outputs, the first and the last measured point are exemplarily shown for the rotational speeds $20000 \mathrm{rpm}$ and $80000 \mathrm{rpm}$.

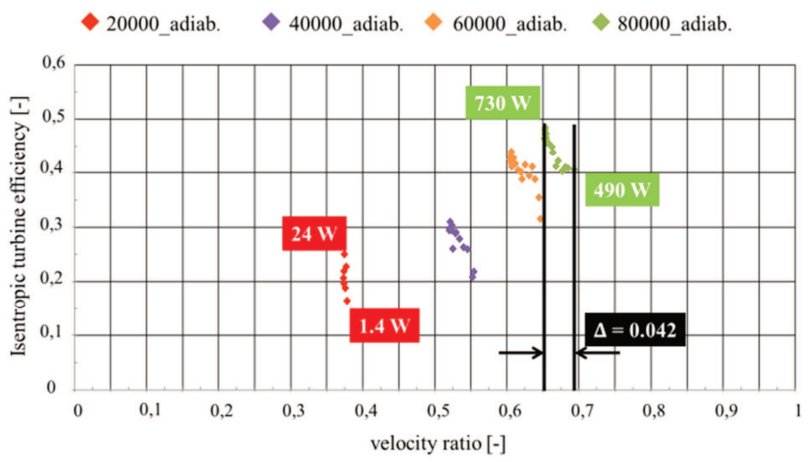

Fig. 4. Measured points - adiabatic

But for generating continuous rising efficiencies in the evaluation, the meter points were reassessed. In this case, only those measured points were used, in which an increased brake load is also accompanied by an increase in the determined turbine efficiency, while the velocity ratio is reduced at the same time. As a further criterion the compressor power was used. Here, only the measured points were turned to account, where the increase of the brake load is accompanied by a steady increased compressor power. The result of the reassessment is shown in Fig. 5. The revised measurement results provide a more steady progress due to a reduced dispersion of the measured points. So the course of the turbine efficiency is more obvious. At the rotational speeds 20000 and $40000 \mathrm{rpm}$ the expected typical characteristic curve can be derived from the position of the 
measured points. The positions of the measured points at the speeds $60000 \mathrm{rpm}$ and $80000 \mathrm{rpm}$ are more inconsistent. At $60000 \mathrm{rpm}$ the first measured point gets out of the ordinary run. This one has a low efficiency or a too low velocity ratio. The other points allow realizing the expected run. The measured points for $80000 \mathrm{rpm}$ allow indicating an opposed run for the turbine efficiency.

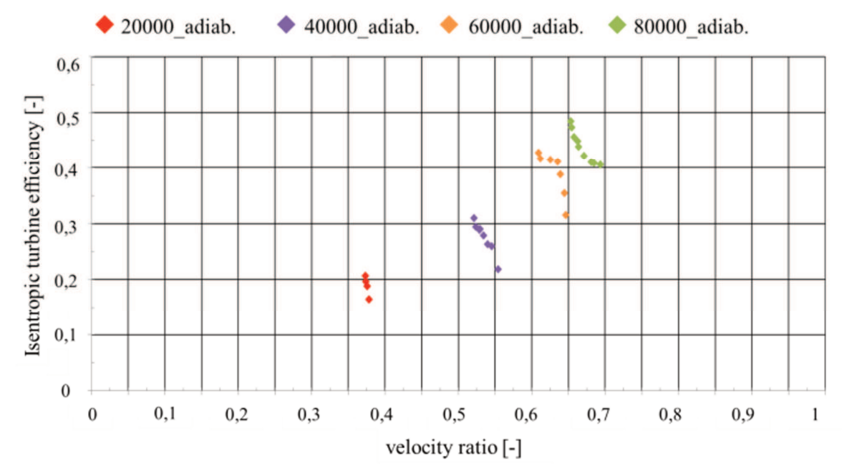

Fig. 5. Revised measuring points - adiabatic

eATL: The generated meter points are shown in Fig. 6 . The measurements provide plausible results. As expected, the maximum efficiency is reached at the highest speed at $80000 \mathrm{rpm}$ and is about $49 \%$.

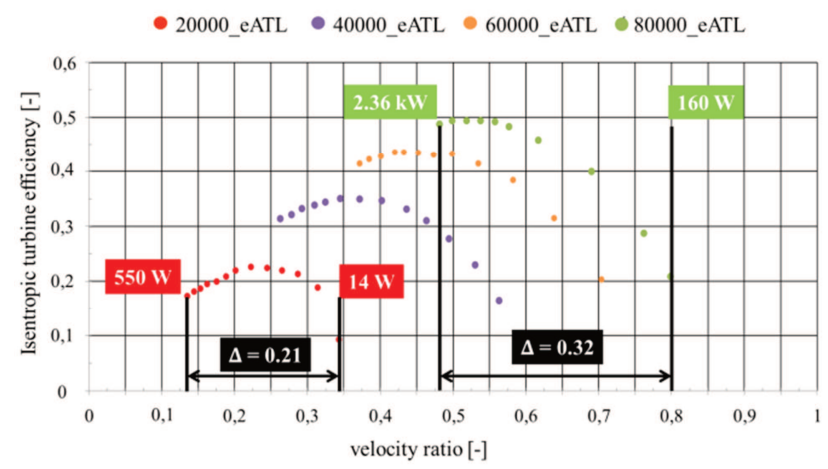

Fig. 6. Measured points - eATL

It is apparent that all measured points have a wide range for generating a reliable run for the turbine efficiency. This wide range is perfectly good to describe the increasing and decreasing efficiency for each measuring graph. The performance of the e-motor allows decelerating the turbine with an output up to 4 kilowatts. For detailed explanation, the outputs for each speed are shown in Fig. 6. The lowest output at $20000 \mathrm{rpm}$ is 14 watts and the major output is 550 watts. The outputs at $80000 \mathrm{rpm}$ are 160 watts and 2.36 kilowatts. The difference between the lowest and highest velocity ratio at $20000 \mathrm{rpm}$ is 0.21 and at $80000 \mathrm{rpm} 0.32$. According to [2], the typically measured velocity ratio is between 0.4 and 0.8 for manufacturers. The results shown in Fig. 6 approximately correspond to the velocity ratio covered by the Ostfalia eATL configuration at the speed of $80000 \mathrm{rpm}$. The lowest velocity ratio provided by the Ostfalia eATL method is 0.135 at the speed of $20000 \mathrm{rpm}$.

\subsection{Preparation of measurement results}

The extrapolated characteristic curve of turbine efficiency is generated with two additional points. Each point represents a turbine efficiency of 0 . The first point with turbine efficiency 0 is in point of origin. It results from a non-rotating turbine. That means that the turbine is braked down by the e-motor and the air mass flow is not able to bring the shaft into rotation. The other point is when velocity of air mass flow rate and circumferential speed of turbine are in balance. Turbine shaft and e-motor are disconnected and so there is no effective work, because turbine output is determined by braking down the friction power of turbocharger bearing. With these two supporting points and the measuring points it's feasible to extrapolate a graph for illustrating the isentropic turbine efficiency. The extrapolation method is a cubic equation. In the following charts the graphs are named as "Poly".

\subsection{Analysis of measurement results}

Figure 7 shows the extrapolated graph of turbine efficiency of the eATL configuration. It highlights that the extrapolation method is almost perfect. In general the measurement produce plausible and repeatable results. The isentropic turbine efficiencies are similar with results which could be found in literature. But in literature are efficiencies around 60 to $70 \%$ in higher rotational speeds [1]. There is a divergence from the first measured points and the extrapolated graph. The reason for the difference could be the low output paired with the low rotational speed. Because of that the influence of troubles is highly and so the turbine efficiency varies in value. For instance, a minimal axially offset of both shafts has a bigger impact in low rotational speeds than in higher speeds. So the influence becomes less in higher rotational speeds. Typically the velocity ratio of turbochargers is between 0.4 and 0.8 [2]. This is comparable with the results of the Ostfalia eATL at $80000 \mathrm{rpm}$.

-20000_eATL • 40000_eATL $\bullet 60000$ eATL $\bullet 80000$ eATL

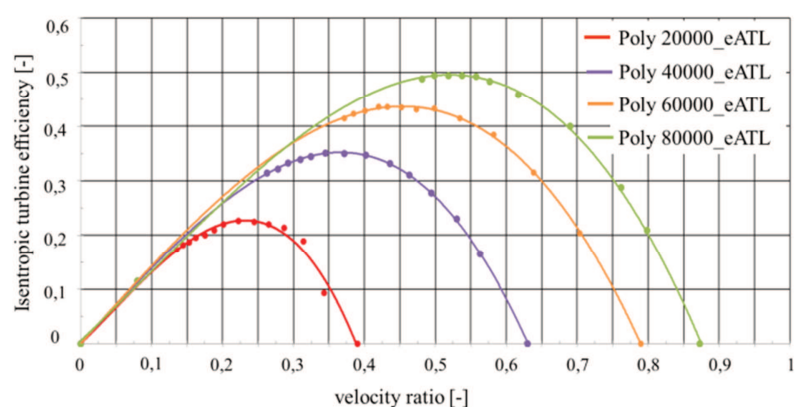

Fig. 7. Extrapolated graph - eATL

Figure 8 shows the comparison of adiabatic and eATL measurement. It's for evaluation of the turbine efficiencies which were obtained with adiabatic configuration. As already said, the revised measurement points were used. It highlights, that the adiabatic method has a high offset to the eATL method. The measured points of $80000 \mathrm{rpm}$ have the largest alignment with the extrapolated graph and the slimmest alignment. For better illustration the offset for each rotational speed of adiabatic method is shown. So the largest difference is in the speed of $20000 \mathrm{rpm}$. There is a dis- 
crepancy of 16.1 percent. The speeds $40000 \mathrm{rpm}$ and 60000 rpm exhibit a discrepancy of round about $7 \%$. The highest nonconformity at $80000 \mathrm{rpm}$ is 4.6 percent. But in all speeds the variance becomes more by increasing the braking power. But the expectation is that the influence of heat flows becomes less with increasing the air mass flow [4].

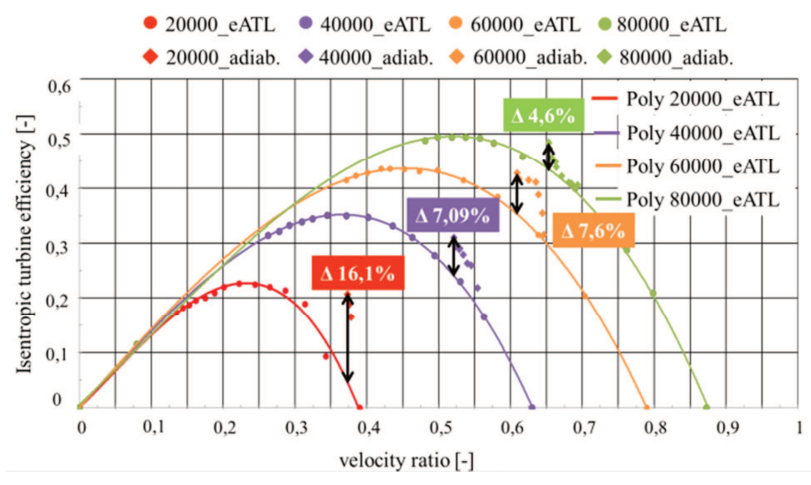

Fig. 8. Extrapolated graph and measuring points of eATL and adiabatic technique

The line graph in Figure 9 deals with the direct comparison of the extrapolated graphs of both methods. The measured points of the adiabatic method were extrapolated, too. But in this case it happened only with an equation of the second degree. The two sampling points with turbine efficiency of zero were used too. But the point with balancing air mass flow ratio and circumferential turbine speed was manually generated. For that reason the highest alignment of measured points and graph were taken as a basis. The line graph clearly shows that the extrapolated turbine efficiencies of adiabatic method for each rotational speed are higher than the extrapolated efficiencies of eATL method. Only a part of the adiabatic $80000 \mathrm{rpm}$ graph matches with the turbine efficiency at the same rotational speed. But an extrapolation without the sampling points would generate a contrary graph run of the adiabatic method. So the results are not really surprising.

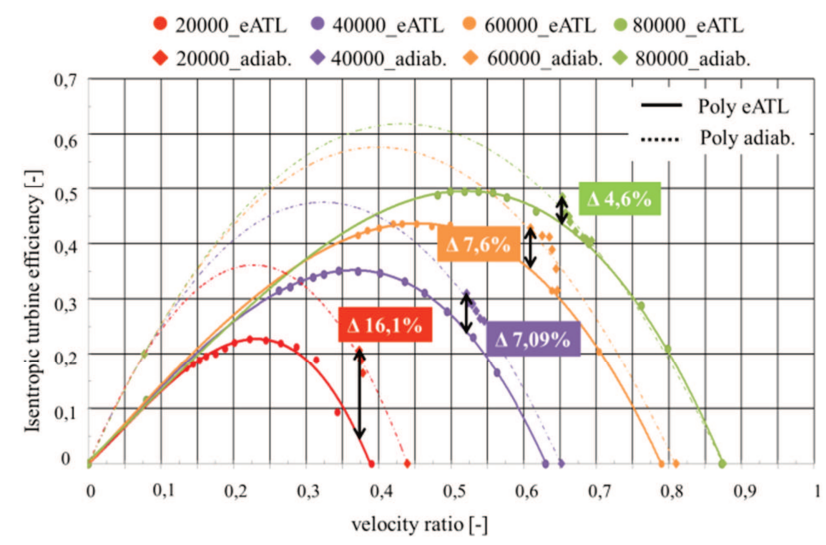

Fig. 9. Direct comparison of extrapolated graphs

\section{Conclusion and prospects}

The methods for measuring turbine efficiencies explained in this paper generate different results. The first is the eATL method and is about an electrical braked down turbine in combination with a torque sensor. With the gained magnitudes it's possible to calculate the isentropic turbine efficiency very easily. On the other hand is the adiabatic method with braking down the turbine with the compressor, as usual. Both techniques conduce for generating turbine maps at low rotational speed ranges. These areas are used for detailed motor process simulations for each operating range. Commonly generated turbine maps on hot gas test benches are not able to acquire measuring points in speed ranges less than $80000 \mathrm{rpm}$.

The adiabatic technique results in higher turbine efficiencies than the Ostfalia eATL. This impact seems to be caused by heat flows from the warmer turbine side into compressor side. At low rotational speeds the heat flows have the biggest influence. Another issue is the narrow range of achievable measuring points using the adiabatic method. One reason is the low air mass flow rate in low speed ranges. Because of the limited maximum braking power of compressor it is not possible to get low velocity ratios. And so it is not possible to get the maximum turbine efficiency. In contrast the eATL is able to gain measurement points from low to high turbine efficiencies. With these results reliable extrapolations of turbine efficiency are feasible. The results of both test procedures include the friction power of the bearing. There is a separate test bench for measuring the friction power of turbocharger bearings of the Ostfalia UAS. With this test bench it is possible to determine friction power for different rotational speeds as well as axial force. In combination of these two test benches the turbine efficiencies without friction power can be determined.

For improving the test procedure of the adiabatic method the compressor air mass flow has to be increased. There is the capability of using the Closed Compressor Loop (CCL) procedure. In CCL procedure the compressed air mass flow returns to the compressor inlet. So it's possible to increase the flow rate at low speed near surge line. Moreover the increasing air mass flow reduces the influences of heat flows on turbine efficiencies. Another possibility is to cool down the compressed turbine air mass flow. With compression the air the temperature increases. A recuperator could be installed in the tube. If necessary a speed controlled fan could be installed additionally. But best solution would be the combination of CCL and active cooling of turbine air mass flow. Integration of these techniques is future development.

\section{Nomenclature}

CCL closed compressor loop

ATL turbocharger

$\mathrm{c}_{\mathrm{p}, \mathrm{C}} \quad$ specific heat capacity at the compressor $c_{p, 3} \quad$ specific heat capacity at the entrance of the turbine

$\mathrm{M}_{\mathrm{ATL}}$ torque at the shaft

$\dot{\mathrm{m}}_{\mathrm{C}} \quad$ compressor air mass flow 
$\dot{\mathrm{m}}_{\mathrm{T}} \quad$ turbine air mass flow

$\mathrm{n}_{\mathrm{ATL}} \quad$ rotational speed of the shaft

$\mathrm{P}_{\mathrm{C}} \quad$ compressor power

$\mathrm{P}_{\mathrm{T}, \text { eATL }}$ braking power of the electric motor

$\mathrm{P}_{\mathrm{ts}, \mathrm{T}, \text { is }}$ isentropic turbine power, total-to-static

$\mathrm{p}_{0} \quad$ atmospheric pressure

$\mathrm{T}_{0} \quad$ ambient air temperature

$\mathrm{T}_{\mathrm{t}, 1} \quad$ total temperature at the entrance of the compressor

$\mathrm{T}_{\mathrm{t}, 2}$
$\mathrm{T}_{\mathrm{t}, 3}$

$\eta_{\mathrm{ts}, \mathrm{T}, \text { is }}$

$\kappa$

$\Pi_{\mathrm{ts}, \mathrm{T}}$

$\varphi_{0}$

$\varphi_{\mathrm{T}}$

$\mathrm{u}_{\mathrm{T}}$

$\mathrm{c}_{0}$ total temperature at the entrance of the turbine isentropic turbine efficiency, total-to-static heat capacity ratio turbine pressure ratio, total-to-static humidity velocity ratio peripheral speed of the turbine wheel approach velocity

\section{Bibliography}

[1] VAN BASSHUYSEN, R., SCHÄFER, F. Handbuch Verbrennungsmotor. Grundlagen, Komponenten, Systeme, Perspektiven. 2015, 7, 554-558.

[2] PISCHINGER, S., SCHARF, J.S., FUNKEN, B., SMILJANOWSKI, V., SCHORN, N. Measurement of turbine efficiency at low turbocharger speeds. 13th Supercharging Conference. 2008, 7.

[3] LÜDDECKE, B. Stationary and non-stationary operating behavior of exhaust gas turbo-chargers. Scientific Series Vehicle Technology. University of Stuttgart, 2016, 1.

[4] GRIGORIADIS, P., BINDER, E., BÖTTCHER, L., BENZ, A., SENS, M. Advanced turbocharger model for 1D ICE simulation - part I. SAE Technical Paper. 2013, 2013-010581 .

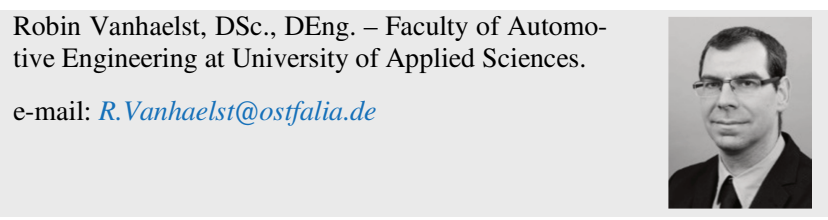

Caroline Bannack, BEng. - Faculty of Automotive Engineering at University of Applied Sciences.

e-mail: Ca.Bannack@ostfalia.de
[5] MAI, H., BOLZ, H. Validierung von Turboladerkennfeldern auf Heißgasprüfständen. ATZ Extra. 2015, 8.

[6] SINAN, Ö. Wärmestromanalyse der Radialturbinenstufe eines PKW-Abgasturboladers mittels numerischer Simulation. Dissertation. 2017.

[7] SAE International; Turbocharger Nomenclature and Terminology SAE J922. 1995.

[8] SAE International, Turbocharger Gas Stand Test code SAE J1826. 1995.

[9] NICKEL, J.; GRIGORIADIS, P., Verfahren und Messmethoden zur Erfassung von Turboladerkennfeldern an Turboladerprüfständen. In: Lechmann, A. (Hrsg.):Simulation und Aufladung von Verbrennungsmotoren. Berlin, Heidelberg: Springer. 2008, 227-244.

Maik Klose, BEng. - Faculty of Automotive Engineering at University of Applied Sciences.

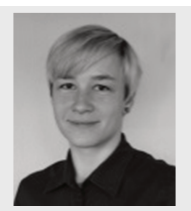

